\title{
H. pylori-infection and antibody immune response in a rural Tanzanian population
}

\author{
Sam M Mbulaiteye ${ }^{* 1}$, Benjamin D Gold ${ }^{2}$, Ruth M Pfeiffer ${ }^{1}$, Glen R Brubaker ${ }^{3}$, \\ John Shao ${ }^{4}$, Robert J Biggar ${ }^{1}$ and Michie Hisada ${ }^{1}$
}

\begin{abstract}
Address: ${ }^{1}$ Division of Cancer Epidemiology and Genetics, National Cancer Institute, NIH, Department of Health and Human Services, Rockville, Maryland, USA, ${ }^{2}$ Division of Pediatric Gastroenterology and Nutrition, Department of Pediatrics, Emory University School of Medicine, Atlanta, Georgia, USA, ${ }^{3}$ Medical Advisor, Interchurch Medical Assistance; New Windsor, Maryland, USA; Formerly, Director, Shirati Hospital, North Mara District, Tanzania and ${ }^{4}$ Department of Medical Microbiology and Immunology, Kilimanjaro Christian Medical Center, Moshi, Tanzania

Email: Sam M Mbulaiteye* - mbulaits@mail.nih.gov; Benjamin D Gold - ben.gold@oz.ped.emory.edu; Ruth M Pfeiffer - pfeiffer@mail.nih.gov; Glen R Brubaker - glenrbrubaker@interchurch.org; John Shao - jshao@kcmc.ac.tz; Robert J Biggar - biggarb@mail.nih.gov;

Michie Hisada - hisadam@mail.nig.gov

* Corresponding author
\end{abstract}

Published: 14 September 2006

Infectious Agents and Cancer 2006, 1:3 doi:10.1 186/1750-9378-1-3
Received: 18 July 2006

Accepted: 14 September 2006

This article is available from: http://www.infectagentscancer.com/content/I/I/3

(c) 2006 Mbulaiteye et al; licensee BioMed Central Ltd.

This is an Open Access article distributed under the terms of the Creative Commons Attribution License (http://creativecommons.org/licenses/by/2.0), which permits unrestricted use, distribution, and reproduction in any medium, provided the original work is properly cited.

\begin{abstract}
Background: Helicobacter pylori $(H$. pylori) infection is ubiquitous in sub-Saharan Africa, but paradoxically gastric cancer is rare.

Methods: Sera collected during a household-based survey in rural Tanzania in 1985 were tested for anti-H. pylori lgG and IgG subclass antibodies by enzyme immunoassay. Odds ratios (OR) and confidence intervals $(\mathrm{Cl})$ of association of seropositivity with demographic variables were computed by logistic regression models.

Results: Of 788 participants, 513 were aged $\leq 17$ years. $H$. pylori seropositivity increased from $76 \%$ at $0-4$ years to $99 \%$ by $\geq 18$ years of age. Seropositivity was associated with age (OR II.5, $95 \% \mathrm{Cl}$ 4.2-31.4 for $10-17$ vs. 0-4 years), higher birth-order (II.I; 3.6-34.I for $\geq 3^{\text {rd }}$ vs. Ist born), and having a seropositive next-older sibling $(2.7 ; 0.9-8.3)$. Median values of $\lg G$ subclass were 7.2 for $\operatorname{lgG} \mid$ and 2.0 for $\operatorname{lgG} 2$. The median $\operatorname{lgG} \mid / \operatorname{lgG} 2$ ratio was 3.I (IQR: I.7-5.6), consistent with a Th2dominant immune profile. Th2-dominant response was more frequent in children than adults (OR 2.4, 95\% Cl 1.3-4.4).

Conclusion: $H$. pylori seropositivity was highly prevalent in Tanzania and the immunological response was Th2-dominant. Th2-dominant immune response, possibly caused by concurrent bacterial or parasitic infections, could explain, in part, the lower risk of $H$. pylori-associated gastric cancer in Africa.
\end{abstract}

\section{Background}

In sub-Saharan Africa, Helicobacter pylori (H. pylori) infection is ubiquitous, with seroprevalence reaching $90 \%$ or higher in many populations [1]. H. pylori is transmitted from person-to-person, and transmission risk is high in populations of low socioeconomic status, poor hygiene, and limited access to clean water [2-4]. The most severe consequence of chronic $H$. pylori infection is gastric adenocarcinoma [1]. However, gastric cancer rates vary widely worldwide and correlate imperfectly with $H$. pylori sero- 
prevalence [5]. For example, seroprevalence reaches $80 \%$ by 5 years of age in sub-Saharan Africa $[6,7]$, highlighting the particularly young age of infection acquisition, and therefore duration of infection. However, age-standardized gastric cancer incidence rates are relatively low at 221 per 100,000 person-years for both males and females [8].

In Japan, seroprevalence increases more gradually with age to a prevalence of $40 \%$ to $70 \%$ among adults $[9,10]$, but the age-standardized gastric cancer incidence rates are substantially higher, ranging from 65-92 and 24-39 per 100,000 person-years among males and females, respectively [8]. By comparison, seroprevalence estimates in the U.S. range from 10 to $20 \%$ among adults $[10,11]$, with the age-standardized gastric cancer incidence rates being 6.6 and 2.6 per 100,000 person-years among white males and females, respectively [8].

These statistics highlight a paradoxical deficit of gastric cancer cases in sub-Saharan Africa, compared to Western countries after controlling for age, the so-called "African enigma" [12]. Gastric cancer deficits may be artifactual, due to incomplete case ascertainment and competing mortality $[13,14]$; however, those reasons do not explain why gastric cancer rates vary in African populations that have comparable access to medical care. Specifically, populations residing in mountainous areas tend to have a higher relative frequency of gastric cancer as compared to populations residing in lowland areas [15].

Variation in gastric cancer rates within Africa, and elsewhere, suggests the presence of modifying factors on $H$. pylori-associated gastric cancer risk. In other words, outcomes of $H$. pylori infection could be influenced by bacterial, host, diet, or other environmental factors. One hypothesis, based on animal studies, posits that bacterial and/or parasitic infections modulate $H$. pylori-induced gastric cancer risk [16], perhaps by altering the quality of $H$. pylori-induced mucosal immunity in the stomach $[17,18]$. H. pylori infection is thought to cause gastric cancer by eliciting vigorous T-helper (Th1) pro-inflammatory cellular immune responses in gastric mucosa [16] and the resulting mucosal injury is mediated by pro-inflammatory cytokines and oxygen radicals secreted by infiltrating chronic inflammatory cells $[16,19]$. Parasites and, to a lesser extent, certain bacterial infections [18], elicit Th2 instead of Th1-dominant immune responses to thwart their elimination [20] and could plausibly modulate $H$. pylori-induced immune response towards one less damaging to the gastric mucosa.

We hypothesized that persons living in high H. pyloriprevalence areas with low gastric-cancer incidence in Africa would therefore have Th2-type dominant $H$. pylori- specific responses. To test this hypothesis, we evaluated $H$. pylori seropositivity and $H$. pylori-specific IgG subclass antibodies in a rural population in northern Tanzania, where H. pylori infection was expected to be endemic and gastric cancer incidence is thought to be low.

\section{Subject selection and serological methods}

The study subjects were residents of the North Mara District, located on the eastern shores of Lake Victoria in Tanzania, who participated in human immunodeficiency virus (HIV) serological surveys from May through June, 1985 [21]. Participants provided individual verbal consent, and parents provided verbal consent for their children, to participate in serological surveys. Institutional Review Boards gave ethical approval for the study. Participants were recruited from households, defined as compounds where individuals shared meals and had one person designated as head. As previously observed [21], polygamy was frequently practiced in this population and headmen often had several wives. The households were randomly selected from nine villages located either on hills $(n=5)$ or in valleys $(n=4)$. Participants provided sociodemographic information and gave a blood sample [21]. The samples were stored at $-80^{\circ} \mathrm{C}$ and were thawed once before current testing. Samples from all but 10 participants enrolled in the original study were available for $H$. pylori serologic testing.

Anti-H. pylori antibodies were measured using an IgG enzyme immunoassay (EIA) as previously reported [2224]. This assay has been validated in various populations, including those from Africa and was shown to have high sensitivity (89-96\%) and specificity (92-97\%), using biopsy-proven $H$. pylori gastric mucosa infection as the gold standard $[22,23]$. The tests were run in triplicate using a standard 96-well microtiter plate and placing the plates on a Benchmark microplate reader (BioRad, Hercules, CA). EIA cut-off values were derived using known $H$. pylori-positive and negative control sera in which OD values $<0.8$ were considered to be negative, OD values $>1.3$ were considered positive, and OD values between 0.8 and 1.3 were considered to be indeterminate, as previously described $[22,24]$. To determine the IgG antibody subclasses (IgG1 or IgG2) in seropositive individuals, as a marker of Th1/2-type cellular response [25], we used IgG subclass EIAs to mouse anti-human IgG1 and mouse antihuman IgG2 conjugated to HRP (Zymed Laboratory, San Francisco, CA). In brief, pooled serum was used as a reference standard for the IgG subclasses. This standard was titrated using each of the IgG subclass antibodies (i.e. mouse anti human IgG1 and mouse anti human IgG2) to determine the highest dilution at which reactivity could still be detected and also remain linear on a standard curve $[22,23,26]$. The maximal dilution for both IgG1 and IgG2 subclasses was 1:25,600. The serum was assigned an 
arbitrary ELISA unit of 1 at this dilution. The ELISA was performed as previously stated using positive controls diluted to $1: 25,600$ based on the previously mentioned standard curve and double the concentration at 1:12,800 dilution. The IgG subclass unit was calculated as ratio of the $\mathrm{OD}_{490}$ of the individual sample to the $\mathrm{OD}_{490}$ of the standard (i.e., IgG subclass unit $=$ sample $\mathrm{OD}_{490} /$ reference $\left.\mathrm{OD}_{490}\right)$. These assays were modified to determine the optimal concentration of antigen in serum and IgG conjugate that discriminated between $H$. pylori-positive and $H$. pylori-negative samples. Each plate incorporated $H$. pylorispecific IgG subclass positive and negative control samples. OD values for IgG1 and IgG2 subclasses were normalized using standards previously reported [22]. We calculated the ratio of IgG1/IgG2 subclasses to determine phenotype of Th1/2-type cellular immune response. Using a previously established criteria to determine Th1 vs. Th2-type response in African and western populations $[27,28]$, an IgG1/IgG2 ratio $>1.0$ suggests a Th2-(IgG1)dominant cellular immune response and a ratio $\leq 1.0$ suggests a Th1-(IgG2)-dominant response.

\section{Statistical analysis}

Associations between sociodemographic variables (sex, age, village location) and $H$. pylori seropositivity were determined using Chi-square or Fisher's exact tests. Because of the high $H$. pylori seroprevalence, we grouped persons with indeterminate status with seronegative individuals for the analysis. Odds ratios (OR) and 95\% confidence intervals $(\mathrm{CI})$ of association of $\mathrm{H}$. pylori seropositivity with age, sex, birth-order were estimated using logistic regression models (PROC GENMOD in SAS 9.1 software package; SAS Institute). Because children are more likely to acquire infection from an infected older sibling, we also estimated the association between seropositivity of a younger child with status of the next-older sibling on whom samples were available. We accounted for intra-familial or intra-household correlations among observations by using generalized estimating equations (25). We used independence working correlation matrices in the computations and checked results by also using equi-correlated working correlations that assumed that members in the same family would have equal correlations. Both methods yielded similar results, so only the results using independent working correlations are presented. Values of $\operatorname{IgG} 1 / \operatorname{IgG} 2$ ratio among seropositive individuals were log-transformed to obtain a normal distribution. We assessed the relationship between the logtransformed IgG1/IgG2 ratio and age in linear regression models. Age was used in the categories 0-4, 5-9, 10-17, and $18+$ years. A two-sided p-value $<0.05$ was considered statistically significant.

\section{Results}

Of 788 participants, 351 (44\%) were male. The majority $513(65 \%)$ were 17 years old or younger (Table 1). Only 2 subjects were HIV-positive, so this variable was not analyzed further. Overall, 725 (92\%) subjects were seropositive for $\mathrm{H}$. pylori antibody; 27 (3\%) were seronegative and $36(5 \%)$ were indeterminate. $H$. pylori seropositivity rose steeply with age from $76 \%$ in children aged $0-4$ years to $99 \%$ in adults $\left(\mathrm{p}_{\text {trend }}<0.001\right.$; Table 1$)$. H. pylori seropositivity was similar among males and females. Among children, those aged 10-17 years were more likely to be $H$. pylori seropositive compared to those aged 0-4 years (OR 11.5, 95\% CI 4.2-31.4; Table 1). Similarly, children of higher birth-order $(\geq 3)$ were more likely to be seropositive compared to first-born children (OR 11.1, 95\% CI 3.6-34.1; Table 1). In a multivariable model, both age group and birth-order were independently associated with $H$. pylori seropositivity (OR 6.3, 95\% CI 1.3-31, for $10-17$ vs. $0-4$ years and OR $4.0,95 \%$ CI $1.1-15$, for $\geq 3^{\text {rd }}$ vs. $1^{\text {st }}$ born). H. pylori seropositivity was marginally higher in children with a seropositive next-older sibling compared to those whose next-older sibling was seronegative (OR 2.7, 95\% CI 0.9-8.3). All 62 married men and their 113 wives were $H$. pylori seropositive. Their concordant results precluded us from evaluating the association of seropositivity between spouses and within parent-child units. H. pylori seropositivity was not associated with location of the village in valleys (OR $0.66 ; 95 \%$ CI $0.33-1.33$ ).

Among seropositive individuals, the median values for the IgG subclass antibodies were IgG1: 7.2 (inter-quartile range [IQR]: 3.6-12.4) and IgG2: 2.0 (IQR: 1.4-3.2). The median IgG1/IgG2 ratio was 3.1 (IQR: 1.7-5.6). Children were more likely to have an IgG1/IgG2 ratio, consistent with Th2-dominant immune response, compared with adults (OR 2.4, 95\% CI 1.3-4.4). In analyses excluding seronegative individuals, the proportion of persons showing Th2-dominant responses increased from 33\% among children aged 1 year to $100 \%$ among children $3-6$ years and then declined somewhat to $80 \%$ among subjects aged 45 years and older (Figure 1, panel A). Similarly, values of the log-transformed IgG1/IgG2 ratio rapidly increased with age to peak between 3-4 years and then reached a plateau in the adult years (Figure 1, panel B). Models of the log-transformed IgG1/IgG2 ratio that included age as a quadratic did not fit the data better than models with linear age (Pearson $\chi^{2}$-test $=0.72$ ). The $\mathrm{IgG} 1 / \mathrm{IgG} 2$ ratio was unrelated to gender, birth order, or village location (data not shown).

\section{Discussion}

We observed extremely high $H$. pylori seroprevalence in a rural population in northern Tanzania. Seropositive individuals showed a high IgG1/IgG2 ratio, suggestive of Th2dominant $H$. pylori-specific immune responses. Our cross- 
Table I: Frequency and risk of $H$. pylori seropositivity among persons residing in rural Tanzania (May to June, 1985)

\begin{tabular}{|c|c|c|c|c|}
\hline Characteristic & No. H. pylori positive/Total No. (\%) & OR & $95 \% \mathrm{Cl}$ & $P$ value \\
\hline Sex $*$ & & & & 0.87 \\
\hline Female & $402 / 436(92 \%)$ & Ref. & & \\
\hline Male & $322 / 351$ (92\%) & 1.04 & $0.67-1.62$ & \\
\hline Age group, years* & & & & $<0.001$ \\
\hline $0-4$ & $|38 /| 8 \mid(76 \%)$ & Ref. & & \\
\hline $5-9$ & $168 / 180(93 \%)$ & 4.4 & $2.42-7.81$ & \\
\hline $10-17$ & | $48 / \mid 52$ (97\%) & 11.5 & $4.22-31.4$ & \\
\hline$\geq 18$ & $264 / 268$ (99\%) & 20.6 & $7.57-56.2$ & \\
\hline Birth orderf & & & & $<0.001$ \\
\hline 1 & $79 / 105$ (75\%) & Ref. & & \\
\hline 2 & $82 / 101$ (91\%) & 3.3 & $1.7-6.8$ & \\
\hline$\geq 3$ & $136 / 139(97 \%)$ & II.I & $3.7-34$ & \\
\hline Next-older sibling \pm & & & & 0.08 \\
\hline Seronegative & $23 / 29(79 \%)$ & Ref. & & \\
\hline Seropositive & I89/208 (91) & 2.70 & $0.90-8.34$ & \\
\hline Location of village & & & & 0.25 \\
\hline Hill & $272 / 290(94 \%)$ & Ref. & & \\
\hline Valley & $453 / 498$ (9।\%) & 0.66 & $0.33-1.33$ & \\
\hline
\end{tabular}

Abbreviations: OR odds ratio; $\mathrm{Cl}$ Confidence Interval

* Sex is missing for one person and age is missing for 7 persons

† Only children with information on birth-order included in this analysis

\pm "Next-older sibling" refers to the next-older sibling of the case child

sectional study confirms high $H$. pylori seropositivity in rural Tanzania, and shows that seropositivity increases steeply with age in childhood and is associated, among children, with higher birth-order and with having a seropositive next-older sibling. These findings are consistent with prior studies of $H$. pylori infection in highly endemic areas $[2,5]$. A novel finding from our study is the Th2dominant $H$. pylori-specific immune responses, which were strongest in children but were present also in adults. As assessed by IgG subclass antibodies, the Th2-dominant immune responses to $H$. pylori infection observed in this rural Tanzanian population contrasts to Th1-dominant responses reported in Western populations $[27,29]$. We speculate that Th2-dominant $H$. pylori-specific immune responses in this population can be modulated by concurrent infection with parasitic or bacterial infections as has been observed in animal models $[16,18]$. Th2-dominance rapidly increased with age and peaked between 3-7 years. This trend with age may reflect a tendency for younger children to have a Th2-dominant pattern or may be due to a high frequency and burden of parasitic and bacterial infections among children, or both. Parasite egg and/or worm burden for schistosomiasis and soil-transmitted helminths have been shown to peak at young ages in this population [30].
Our study highlights one aspect of the gastric cancer paradox in Africa, i.e., early acquisition of $H$. pylori infection in childhood and persistence of seropositivity into adulthood in an area where gastric cancer is relatively rare. Competing mortality (causing deficits in the elderly population $\geq 60$ years) has been advanced as one explanation for the lower age-sex specific gastric cancer incidence in sub-Saharan Africa compared to developed countries. However, this explanation is not supported by data from South Africa where life expectancy prior to the AIDS epidemic was 63 years [31]. Investigators at Shirati Hospital, North Mara District, who serve our study population and are actively engaged in cancer research [32], previously reported gastric cancer to be rare. In an analysis of 279 malignancies seen at the Hospital from 1952-1965, only $12(4.3 \%)$ were diagnosed as gastric cancer [33]. Conversely, gastric cancer is relatively more frequent on the slopes of Mount Kilimanjaro, where it contributes 15\% of malignancies [34]. Moreover, there are similar reports of higher gastric cancer rates in mountainous or dry areas elsewhere in Africa $[15,35,36]$. The variation in relative frequency of gastric cancer in the context of similar $H$. pylori prevalence, similar access to medical care, and similar life expectancy has led to the hypothesis that environmental co-factors, perhaps diet (nitrates or fresh fruits and 

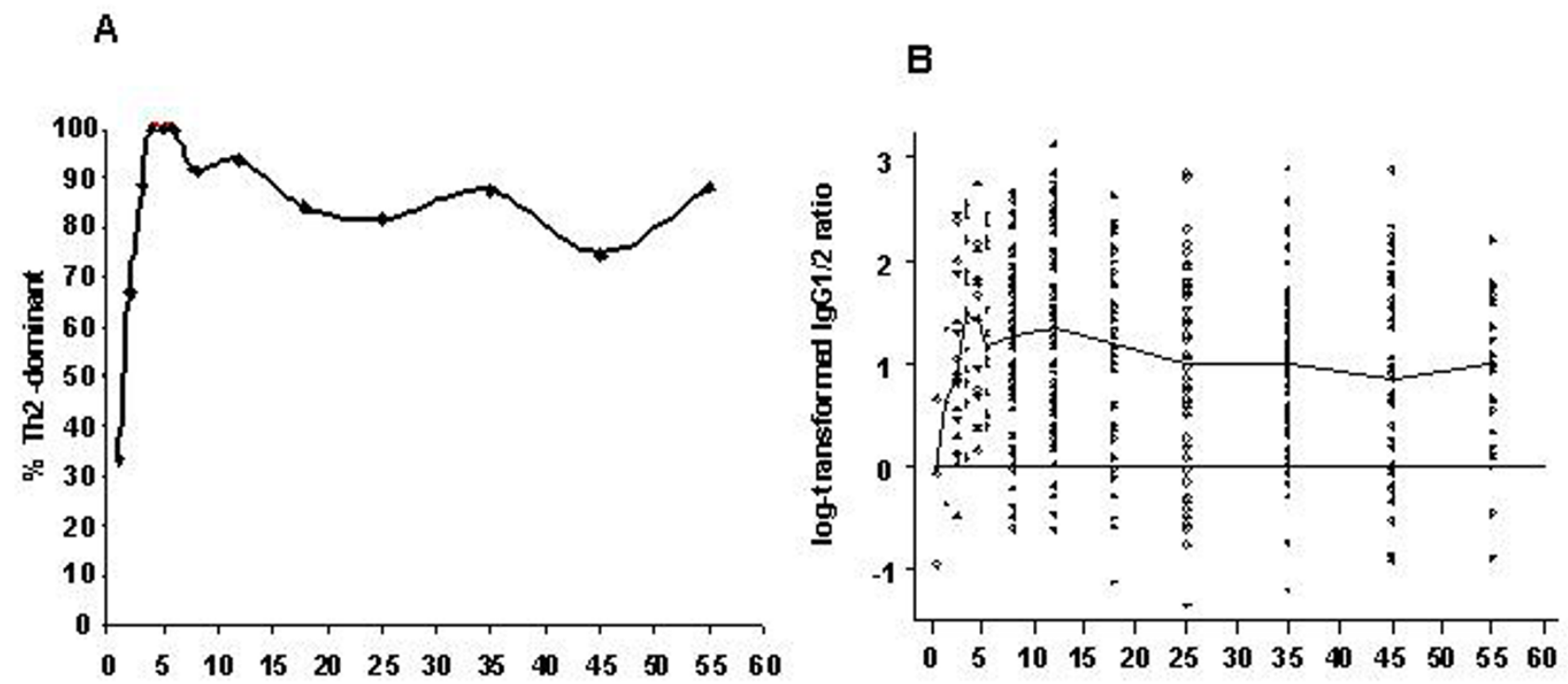

Agegroup, years

\section{Figure I}

Th2 type response by age group, in years: Panel A: Percent of $H$. pylori seropositive individuals with Th2-dominant lgG $H$. pylori specific immune response by age group. Panel B: Log-transformed lgG I/lgG2 ratio by age group among $H$. pylori seropositive individuals in rural Tanzania. The $X$-axis shows age groups in years, the $Y$-axis shows log-transformed values. The $y$-line marks the cut-off value for T helper (Th)-dominant I vs. Th2-dominant response: values above the line indicate Th2-dominant responses, while values below the line indicate ThI-dominant responses. The line plot connects the median log-transformed $\operatorname{lgGl} / 2$ ratios for each age group and the scattered points indicate actual values for each age group.

vegetables), are important. However, no dietary factors have been convincingly implicated in Africa. An alternative hypothesis posits that enteric or other parasites may influence gastric cancer risk [16]. This hypothesis is based on the observations in mice that Helicobacter-induced gastric atrophy, a precursor lesion to gastric cancer, improved in mice concurrently infected with enteric parasites but not in mice that were not. Improvements were associated with concomitant down-regulation of the pro-inflammatory responses due to a shift from Th1 toward Th2-dominant cellular immune response in mice with concurrent enteric parasite infection [16]. Our finding of Th2-dominant immune response in $H$. pylori infected persons from northern rural Tanzania, where gastric cancer is relatively rare, is consistent with this hypothesis. Although we lack data on parasite or colonic bacterial infections, it is reasonable to assume that people who live in remote rural African villages without access to running water or other amenities, such as ours, are frequently infected with parasitic and/or bacterial conditions in addition to $H$. pylori [30,37].
The role of Th1/2 immunity and H. pylori-induced gastric cancer has been investigated in two prior studies. In one conducted in Soweto, South Africa, where gastric cancer incidence is low, found Th2-dominant $H$. pylori-specific immune responses in blacks with gastric symptoms [27] whereas study of symptomatic white subjects from Austria and Germany, where gastric cancer incidence is high, demonstrated Th1-dominant responses [27]. The authors suggested that the Th2-dominant responses in blacks were likely induced by co-infection with parasites, which they postulated may modulate gastric risk cancer among Africans. In the other study conducted in Columbia in persons from low and mountainous regions where gastric cancer incidence is low and high, respectively, evaluated H. pylori seropositivity and parasitic infections. Persons from Tumaco, a low lying area where gastric cancer incidence is low, had Th2-dominant immune responses and a higher prevalence of helminth infections [28]. Conversely, those from Pasto, a high altitude area where gastric cancer incidence is high, had predominantly Th1dominant immune responses and a lower prevalence of 
helminth infections [28]. The authors attributed differences in Th1 or Th2-dominant responses across the low vs. mountainous regions to differences the prevalence of helminth infections and suggested that parasitic infection may modify $H$. Pylori-induced gastric cancer risk in Columbia. Thus, those studies and ours lend support to the hypothesis that Th1/2 immunity modulated by parasite infections may influence the risk of $\mathrm{H}$. pylori-associated gastric cancer in diverse environments $[15,28,35,36]$.

Our study has some limitations. H. pylori infection was measured using serological assays, and some subjects may have been misclassified. The finding of almost universal seropositivity among adults is surprising because we would have expected a small proportion of individuals to be seronegative due to loss of bacterial colonization that occurs with age in chronically infected persons or with development of chronic gastric atrophy. We lacked endoscopy data on the state of gastric mucosa (presence of ulcer, gastric atrophy or not) and therefore are unable to draw conclusions about the relationship between Th2 dominance and severity of gastric mucosal inflammation. Direct measurement of pepsinogen levels could have also provided some information on the presence or not of gastric atrophy, but the volume of residual samples from the study population were inadequate for additional testing. Furthermore, our study was cross-sectional so we cannot infer temporality of associations demonstrated. We note that our "highland" area villages were in low hills, not mountainous areas, thus our study does not provide data for Th1 vs. Th2 responses in low vs. mountainous regions in Africa. The use of IgG subclasses assays as markers for type1/2-dominant immune response in a general population in Africa is novel, and our study provides valuable baseline data for sub-Saharan Africa. Finally, IgE measurements would strengthen our results on the role of parasites, but we lacked a validated assay to perform IgE studies.

To conclude, $H$. pylori seropositivity was highly prevalent in rural Tanzania. Seropositive persons showed a Th2dominant immune response to $H$. pylori infection, which may be due to effects of concurrent infection with parasites and/or bacterial infections. We speculate that the shifts in immune response from Th1 responses to Th2 responses in early childhood and persistence of that immune profile into adulthood may partially explain the paradoxically lower gastric cancer risk in highly $H$. pyloriendemic Africa.

\section{Competing interests}

The author(s) declare that they have no competing interests.

\section{Authors' contributions}

SMM conceived of the study, contributed to analysis and interpretation of data, and drafted the manuscript. BDG carried out the serological studies, contributed to interpretation of data and writing the report. RMP carried out the statistical analyses and interpreted data. GRB and JCS did the field work, contributed to interpretation of data. RJB participated in the design of the study, field work, and contributed to analysis and edited the manuscript. $\mathrm{MH}$ participated in study design and coordination and helped with analysis, interpretation of data, and editing the manuscript. All authors read and approved the final manuscript.

\section{Acknowledgements}

We thank participants in the survey and Tanzanian authorities for permitting this work to be done. We are grateful to Frances Yellin (Computer Services, Ltd, Rockville) for preparing the data files, to Violet Devairakkam (Research Triangle Institute, Rockville) for handling the samples, to Dexter Thompson (Division of Pediatric Gastroenterology and Nutrition, Department of Pediatrics, Emory University School of Medicine) for performing $\mathrm{H}$. pylori serology, and to James J. Goedert for comments on the manuscript. This project was funded by the Intramural Research Program of the National Cancer Institute, National Institutes of Health, Department of Health and Human Services, under Purchase Order number 263-NQ320842.

\section{References}

I. Schistosomes, liver flukes and Helicobacter pylori. IARC Working Group on the Evaluation of Carcinogenic Risks to Humans. Lyon, 7-I4 June I 994. IARC Monogr Eval Carcinog Risks Hum 1994, 6l: I-24I.

2. Goodman KJ, Correa P: Transmission of Helicobacter pylori among siblings. Lancet 2000, 355:358-362.

3. Rothenbacher D, Bode G, Berg G, Gommel R, Gonser T, Adler G, Brenner $\mathrm{H}$ : Prevalence and determinants of Helicobacter pylori infection in preschool children: a population-based study from Germany. Int J Epidemiol I998, 27:I35-|4I.

4. Teh BH, Lin JT, Pan WH, Lin SH, Wang LY, Lee TK, Chen C): Seroprevalence and associated risk factors of Helicobacter pylori infection in Taiwan. Anticancer Res 1994, I4: I 389-1392.

5. Holcombe C, Umar H, Lucas SB, Kaluba J: Low incidence of clinically significant gastroduodenal pathology despite a high incidence of Helicobacter pylori infection. Trans $R$ Soc Trop Med Hyg 1994, 88:569-57I.

6. Lindkvist P, Enquselassie F, Asrat D, Nilsson I, Muhe L, Giesecke J: Helicobacter pylori infection in Ethiopian children: a cohort study. Scand J Infect Dis 1999, 3 I:475-480.

7. Thomas JE, Dale A, Harding M, Coward WA, Cole TJ, Weaver LT: Helicobacter pylori colonization in early life. Pediatr Res 1999 , 45:218-223.

8. Parkin DM, Whelan SL, Ferlay J, Teppo L, Thomas DB: Cancer Incidence In Five Continents. IARC Sci Publ 2002, I 55:258-269.

9. Yamashita Y, Fujisawa T, Kimura A, Kato H: Epidemiology of Helicobacter pylori infection in children: a serologic study of the Kyushu region in Japan. Pediatr Int 200 I, 43:4-7.

10. Epidemiology of, and risk factors for, Helicobacter pylori infection among 3194 asymptomatic subjects in 17 populations. The EUROGAST Study Group. Gut 1993, 34:1672-I676.

II. Malaty HM, El-Kasabany A, Graham DY, Miller CC, Reddy SG, Srinivasan SR, Yamaoka Y, Berenson GS: Age at acquisition of Helicobacter pylori infection: a follow-up study from infancy to adulthood. Lancet 2002, 359:931-935.

12. Campbell DI, Warren BF, Thomas JE, Figura N, Telford JL, Sullivan PB: The African enigma: low prevalence of gastric atrophy, high prevalence of chronic inflammation in West African adults and children. Helicobacter 200I, 6:263-267. 
13. Agha A, Graham DY: Evidence-based examination of the African enigma in relation to Helicobacter pylori infection. Scand J Gastroenterol 2005, 40:523-529.

14. Bravo LE, van Doom LJ, Realpe JL, Correa P: Virulence-associated genotypes of Helicobacter pylori: do they explain the African enigma? Am J Gastroenterol 2002, 97:2839-2842.

15. McFarlane G, Forman D, Sitas F, Lachlan G: A minimum estimate for the incidence of gastric cancer in Eastern Kenya. Br J Cancer 200I, 85: I322-I325

16. Fox JG, Beck P, Dangler CA, Whary MT, Wang TC, Shi HN, NaglerAnderson C: Concurrent enteric helminth infection modulates inflammation and gastric immune responses and reduces helicobacter-induced gastric atrophy. Nat Med 2000, 6:536-542.

17. Selin LK, Cornberg M, Brehm MA, Kim SK, Calcagno C, Ghersi D, Puzone R, Celada F, Welsh RM: CD8 memory T cells: cross-reactivity and heterologous immunity. Semin Immunol 2004, 16:335-347.

18. Williams $A E$, Edwards $L$, Hussell $\mathrm{T}$ : Colonic bacterial infection abrogates eosinophilic pulmonary disease. J Infect Dis 2006, 193:223-230.

19. Bamford KB, Fan X, Crowe SE, Leary JF, Gourley WK, Luthra GK, Brooks EG, Graham DY, Reyes VE, Ernst PB: Lymphocytes in the human gastric mucosa during Helicobacter pylori have a $\mathbf{T}$ helper cell I phenotype. Gastroenterology 1998, I I 4:482-492.

20. Maizels RM, Yazdanbakhsh M: Immune regulation by helminth parasites: cellular and molecular mechanisms. Nat Rev Immunol 2003, 3:733-744.

21. Mbulaiteye SM, Pfeiffer RM, Whitby D, Brubaker GR, Shao J, Biggar RJ: Human Herpesvirus 8 Infection within Families in Rural Tanzania. J Infect Dis 2003, 187: I780-I785.

22. Gold BD, Khanna B, Huang LM, Lee CY, Banatvala N: Helicobacter pylori acquisition in infancy after decline of maternal passive immunity. Pediatr Res 1997, 41:641-646.

23. Khanna B, Cutler A, Israel NR, Perry M, Lastovica A, Fields PI, Gold BD: Use caution with serologic testing for Helicobacter pylori infection in children. I Infect Dis 1998, I78:460-465.

24. Hisada M, Lee MG, Hanchard B, Owens M, Song Q, van Doorn LJ, Cutler AF, Gold BD: Characteristics of Helicobacter pylor infection in Jamaican adults with gastrointestinal symptoms. J Clin Microbiol 200I, 39:212-216.

25. Mawas F, Feavers IM, Corbel MJ: Serotype of Streptococcus pneumoniae capsular polysaccharide can modify the ThI/ Th2 cytokine profile and IgG subclass response to pneumococal-CRM(197) conjugate vaccines in a murine model. Vaccine 2000, 19: II59-II66.

26. Campbell DI, Pearce MS, Parker L, Thomas JE, Sullivan PB, Dale A: Immunoglobulin G subclass responses to Helicobacter pylor vary with age in populations with different levels of risk of gastric carcinoma. Clin Diagn Lab Immunol 2004, I I:63 I-633.

27. Mitchell HM, Ally R, Wadee A, Wiseman M, Segal I: Major differences in the IgG subclass response to Helicobacter pylori in the first and third worlds. Scand J Gastroenterol 2002, 37:5 I 7-522.

28. Whary MT, Sundina N, Bravo LE, Correa P, Quinones F, Caro F, Fox JG: Intestinal helminthiasis in Colombian children promotes a Th2 response to Helicobacter pylori: possible implications for gastric carcinogenesis. Cancer Epidemiol Biomarkers Prev 2005, | 4: |464-| 469 .

29. Segal I, Ally R, Mitchell H: Gastric cancer in sub-Saharan Africa. Eur J Cancer Prev 200I, I0:479-482.

30. Poggensee G, Krantz I, Nordin P, Mtweve S, Ahlberg B, Mosha G, Freudenthal S: A six-year follow-up of schoolchildren for urinary and intestinal schistosomiasis and soil-transmitted helminthiasis in Northern Tanzania. Acta Trop 2005, 93: $131-140$

31. Kuipers EJ, Meijer GA: Helicobacter pylori gastritis in Africa. Eur I Gastroenterol Hepatol 2000, 1 2:60 I-603.

32. Brubaker G, Levin AG, Steel CM, Creasey G, Cameron HM, Linsell CA, Smith PG: Multiple cases of Burkitt's lymphoma and other neoplasms in families in the North Mara District of Tanzania. Int J Cancer 1980, 26:165-170.

33. Eshleman JL: A study of the relative incidence of malignant tumours seen at Shirati Hospital in Tanzania. East Afr Med J 1966, 43:274-283.
34. Kitinya JN, Lauren PA, Jones ME, Paljarvi L: Epidemiology of intestinal and diffuse types of gastric carcinoma in the Mount Kilimanjaro area, Tanzania. Afr J Med Med Sci 1988, 17:89-95.

35. Templeton AC, Hutt MS: Distribution of tumours in Uganda. Recent Results Cancer Res 1973, 41:I-22.

36. Madebo T, Lindtjorn B, Henriksen TH: High incidence of oesophagus and stomach cancers in the Bale highlands of south Ethiopia. Trans R Soc Trop Med Hyg 1994, 88:415.

37. Handzel T, Karanja DM, Addiss DG, Hightower AW, Rosen DH, Colley DG, Andove J, Slutsker L, Secor WE: Geographic distribution of schistosomiasis and soil-transmitted helminths in Western Kenya: implications for anthelminthic mass treatment. Am J Trop Med Hyg 2003, 69:3 I8-323.
Publish with Bio Med Central and every scientist can read your work free of charge

"BioMed Central will be the most significant development for disseminating the results of biomedical research in our lifetime. "

Sir Paul Nurse, Cancer Research UK

Your research papers will be:

- available free of charge to the entire biomedical community

- peer reviewed and published immediately upon acceptance

- cited in PubMed and archived on PubMed Central

- yours - you keep the copyright 